\title{
The Empirical Forcing Function as a tool for the diagnosis of large-scale atmospheric anomalies
}

\author{
C. Andrade ${ }^{1,2}$, J. A. Santos ${ }^{3}$, J. G. Pinto ${ }^{4}$, J. Corte-Real ${ }^{2}$, and S. Leite ${ }^{3}$ \\ ${ }^{1}$ Polytechnic Institute of Tomar, Portugal \\ ${ }^{2}$ ICAAM: Group Water, Soil and Climate, University of Évora, Portugal \\ ${ }^{3}$ CITAB, University of Trás-os-Montes e Alto Douro, Portugal \\ ${ }^{4}$ Institute for Geophysics and Meteorology, University of Cologne, Germany
}

Received: 8 May 2009 - Revised: 4 January 2010 - Accepted: 6 January 2010 - Published: 15 January 2010

\begin{abstract}
The time-mean quasi-geostrophic potential vorticity equation of the atmospheric flow on isobaric surfaces can explicitly include an atmospheric (internal) forcing term of the stationary-eddy flow. In fact, neglecting some nonlinear terms in this equation, this forcing can be mathematically expressed as a single function, called Empirical Forcing Function (EFF), which is equal to the material derivative of the time-mean potential vorticity. Furthermore, the EFF can be decomposed as a sum of seven components, each one representing a forcing mechanism of different nature. These mechanisms include diabatic components associated with the radiative forcing, latent heat release and frictional dissipation, and components related to transient eddy transports of heat and momentum. All these factors quantify the role of the transient eddies in forcing the atmospheric circulation. In order to assess the relevance of the EFF in diagnosing large-scale anomalies in the atmospheric circulation, the relationship between the EFF and the occurrence of strong North Atlantic ridges over the Eastern North Atlantic is analyzed, which are often precursors of severe droughts over Western Iberia. For such events, the EFF pattern depicts a clear dipolar structure over the North Atlantic; cyclonic (anticyclonic) forcing of potential vorticity is found upstream (downstream) of the anomalously strong ridges. Results also show that the most significant components are related to the diabatic processes. Lastly, these results highlight the relevance of the EFF in diagnosing large-scale anomalies, also providing some insight into their interaction with different physical mechanisms.
\end{abstract}

Keywords. Meteorology and atmospheric dynamics (Climatology; General circulation; Synoptic-scale meteorology)

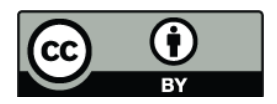

Correspondence to: C. Andrade (c.andrade@ipt.pt)

\section{Introduction}

The temporal mean flow of the atmosphere can be regarded as a forced regime that is conditioned by several factors, e.g., heat release, topography and surface thermal contrasts (Wallace and Hobbs, 2006). However, eddies embedded in the time-mean flow induce local transient heat and momentum fluxes that are key forcing mechanisms of the general atmospheric circulation. In fact, such eddies are essential for explaining the energy cycle of the atmosphere, as they continuously transform zonal-mean available potential energy into eddy and zonal-mean kinetic energy of the flow that is ultimately dissipated through cascading frictional dissipation processes (e.g., Peixoto and Oort, 1992). The key role played by the eddy transports concerning the maintenance of largescale atmospheric anomalies through their interaction with the zonal-mean flow has been already demonstrated in many previous studies (e.g., Edmon et al., 1980; Holopainen et al., 1982; Hoskins and Valdes, 1990; Lau and Nath, 1991; Black, 1998; Santos et al., 2009b).

Vorticity is a widely used property when describing the dynamical characteristics of the flow, and its equation is commonly used for diagnosis and prediction of fluid motions (Hoskins et al., 1985; Holton, 2004). Potential vorticity is a quantity that combines vorticity and static stability and verifies an invertibility principle that can be stated as follows (Bluestein, 1993): if the distribution of potential vorticity is known, then vorticity, static stability and wind field can also be determined, providing the required boundary conditions and a condition. The concept of potential vorticity is often used in the study of the atmospheric circulation, particularly when considering an adiabatic frictionless flow (Salby and Roger, 1996); in this case it is materially conserved (local rate of change is entirely balanced by advection). Therefore, potential vorticity is commonly written in its original formulation on isentropic surfaces (Ertel, 1942). However, many

Published by Copernicus Publications on behalf of the European Geosciences Union. 
subsequent studies have also used the potential vorticity defined on isobaric surfaces (e.g., Hartmann, 1977; Lau and Wallace, 1979). In fact, potential vorticity is also materially conserved when using the quasi-geostrophic formulation of the potential vorticity under the quasi-geostrophic assumptions and following the geostrophic wind on an isobaric surface (Holton, 2004).

The mathematical formulation of the quasi-geostrophic potential vorticity equation in isobaric coordinates is revisited in the present study. Some mathematical approximations and rearrangements are undertaken so as to obtain a linearized version of the equation, where various forcing terms are explicitly and independently represented. The forcing term of the stationary-eddy (asymmetric) potential vorticity is expressed as a single function, called the Empirical Forcing Function (hereafter EFF). This function can be in turn decomposed as a sum of seven components that represent different physical contributions (associated with diabatic processes and transient eddy enthalpy and momentum transports) to the total forcing term of the balance equation. This development closely follows the original formulation undertaken by Saltzman (1962).

In order to illustrate the applicability of the EFF in diagnosing large-scale atmospheric anomalies, a case study focusing on the establishment of ridges over the Eastern North Atlantic is presented. Previous studies have shown that the frequency and persistence of such events are often associated with droughts over western Iberia (Santos et al., 2007a). Here, precipitation is characterized by a strong seasonal behaviour reaching a maximum during the winter season (December to February; hereafter DJF). As a result, extremely wet or extremely dry winters tend to have strong impacts on water availability and management practices (García-Herrera et al., 2007). Due to this vulnerability, with great environmental, economical and social significance, it is of great importance to better understand the large-scale mechanisms that are linked to the occurrence of such droughts.

The influence of these enhanced ridges over the Eastern North Atlantic in the mid-latitude weather systems is also tested here. In fact, these systems have their origin in processes predicted under the theory of baroclinic instability and their development is closely associated with the above referred forcing mechanisms. Such extra-tropical migratory systems follow a path in the belt of the prevailing westerly winds and derive their existence and growth from the conversion of available potential energy to kinetic energy by diminishing the temperature gradients, lifting mid-latitude warm air and sinking cold polar air (Charney, 1947; Eady, 1949). They also play a central role in the angular momentum budget of the atmosphere and are primarily responsible for maintaining the westerlies against surface friction (Peixoto and Oort, 1992). One common measure of synoptic activity is the "storm track", which Blackmon (1976) defined as the standard deviation of the bandpass-filtered (2-6 days) variability at $500 \mathrm{hPa}$. This variable has been widely used to quantify synoptic activity, both for observational and model data sets (e.g., Hoskins and Valdes, 1990; Stephenson and Held, 1993; Chang and Fu, 2002; Yin, 2005; Ulbrich et al., 2008; Chang, 2009).

In this study, the objectives are then two-fold. First, it is intended to present the mathematical development of the EFF, and secondly, to demonstrate its relevance in diagnosing large-scale anomaly patterns by considering a pertinent case study. The structure of this text is as follows: Sect. 2 presents the mathematical formulation of the EFF; Sect. 3 describes data and methodologies; Sect. 4 presents the results obtained for the selected case study and, lastly, Sect. 5 discusses the main results of this study.

\section{Mathematical development of the Empirical Forcing Function}

\subsection{Fundamental equations and Empirical Forcing Function deduction}

The mathematical development of the EFF involves fundamental equations and definitions and was first presented by Saltzman (1962). The following notation is used in the development; $\overline{()}$ represents the time-mean, ()$^{\prime}$ time-mean departure, \langle\rangle represents the zonal-mean (average taken over a parallel) and ()* the zonal-mean departure. Considering the time-mean primitive equations of motion in spherical coordinates, after Reynolds decomposition $\left(\omega=\bar{\omega}+\omega^{\prime}\right)$, the zonal momentum equation can be written as

$$
\frac{\partial \bar{u}}{\partial t}+\bar{v} \bullet \nabla \bar{u}+\bar{\omega} \frac{\partial \bar{u}}{\partial p}=\left(f+\frac{\bar{u} \tan \varphi}{a}\right) \bar{v}-\frac{1}{a \cos \varphi} \frac{\partial \bar{\Phi}}{\partial \lambda}+\bar{X}(1)
$$

and the meridional momentum equation as

$$
\frac{\partial \bar{v}}{\partial t}+\bar{v} \bullet \nabla \bar{v}+\bar{\omega} \frac{\partial \bar{v}}{\partial p}=-\left(f+\frac{\bar{u} \tan \varphi}{a}\right) \bar{u}-\frac{1}{a} \frac{\partial \bar{\Phi}}{\partial \varphi}+\bar{Y}
$$

where variables $\bar{X}$ and $\bar{Y}$ can be defined as

$$
\begin{aligned}
\bar{X}= & \overline{F_{\lambda}}-\left[\frac{1}{a \cos \varphi} \frac{\partial \overline{u^{\prime 2}}}{\partial \lambda}+\frac{1}{a \cos \varphi} \frac{\partial}{\partial \varphi} \overline{u^{\prime} v^{\prime}} \cos \varphi\right. \\
& \left.+\frac{\partial \overline{u^{\prime} \omega^{\prime}}}{\partial p}-\frac{\overline{u^{\prime} v^{\prime}} \tan \varphi}{a}\right] \\
\bar{Y}= & \overline{F_{\varphi}}-\left[\frac{1}{a \cos \varphi} \frac{\partial \overline{v^{\prime} u^{\prime}}}{\partial \lambda}+\frac{1}{a \cos \varphi} \frac{\partial}{\partial \varphi} \overline{v^{\prime 2}} \cos \varphi\right. \\
& \left.+\frac{\partial \overline{v^{\prime} \omega^{\prime}}}{\partial p}+\frac{\overline{u^{\prime 2}} \tan \varphi}{a}\right]
\end{aligned}
$$

The time-mean energy equation, also after Reynolds decomposition, can be written as follows

$$
\frac{\partial \bar{T}}{\partial t}+\overline{\boldsymbol{v}} \bullet \nabla \bar{T}+\bar{\omega} \frac{\partial \bar{T}}{\partial p}=\frac{R}{p c_{p}} \bar{\omega} \bar{T}+\bar{Q}
$$


where variable $\bar{Q}$ can be defined as

$$
\begin{aligned}
\bar{Q}=\frac{\overline{\dot{q}_{\mathrm{F}}+\dot{q}_{\mathrm{R}}+\dot{q}_{\mathrm{L}}}}{c_{p}}- & {\left[\frac{1}{a \cos \varphi} \frac{\partial \overline{u^{\prime} T^{\prime}}}{\partial \lambda}+\frac{1}{a \cos \varphi} \frac{\partial}{\partial \varphi} \overline{v^{\prime} T^{\prime}} \cos \varphi\right.} \\
& \left.+\frac{\partial \overline{\omega^{\prime} T^{\prime}}}{\partial p}-\frac{R}{p c_{p}} \overline{\omega^{\prime} T^{\prime}}\right]
\end{aligned}
$$

In the previous equation, $\dot{q}_{\mathrm{R}}, \dot{q}_{\mathrm{F}}$ and $\dot{q}_{\mathrm{L}}$ are the rates of heat addition per unit mass due to radiation, conduction and friction and latent heat release, respectively.

Now consider the continuity equation

$\frac{\partial \omega}{\partial p}+\nabla \bullet v=0$,

the hydrostatic equation

$$
\frac{\partial \Phi}{\partial p}=-\frac{R T}{p}
$$

and the stability parameter

$\Gamma=\frac{T}{\theta} \frac{\partial \theta}{\partial p}=\frac{\partial T}{\partial p}-\frac{R T}{p c_{p}}$,

which is considered constant at each isobaric level (Saltzman, 1962; Savijärvi, 1978). Finally, consider the quasigeostrophic potential vorticity definition (Savijärvi, 1978; Holton, 2004), П,

$$
\Pi=\eta+f \frac{\partial}{\partial p}\left(\frac{T}{\Gamma}\right)
$$

where $\eta=\zeta+f$ is the absolute vorticity, $\zeta$ the relative vorticity, $f=2 \Omega \cos \varphi$ the planetary vorticity and $f \frac{\partial}{\partial p}\left(\frac{T}{\Gamma}\right)$ the stretching vorticity (Holton, 2004).

From the quasi-geostrophic potential vorticity definition, after applying the local time-derivative, the next relation is obtained

$$
\frac{\partial \Pi}{\partial t}=\frac{\partial \eta}{\partial t}+\frac{\partial}{\partial t}\left(f \frac{\partial}{\partial p}\left(\frac{T}{\Gamma}\right)\right)
$$

as well as the following vector decomposition

$\boldsymbol{v} \bullet \nabla \Pi=\boldsymbol{v} \bullet \nabla \eta+\boldsymbol{v} \bullet \nabla\left(f \frac{\partial}{\partial p}\left(\frac{T}{\Gamma}\right)\right)$.

Adding to the vorticity equation

$$
\frac{\partial \eta}{\partial t}+\boldsymbol{v} \bullet \nabla \eta+\omega \frac{\partial \eta}{\partial p}+\eta \nabla \bullet \boldsymbol{v}+\boldsymbol{k} \nabla \omega \times \frac{\partial v}{\partial p}-\boldsymbol{k} \bullet \nabla \times F=0,
$$

the terms $\frac{\partial}{\partial t}\left(f \frac{\partial}{\partial p}\left(\frac{T}{\Gamma}\right)\right)+v \bullet \nabla\left(f \frac{\partial}{\partial p}\left(\frac{T}{\Gamma}\right)\right)$, the following equation is obtained

$$
\begin{aligned}
\underbrace{\frac{\partial \eta}{\partial t}}_{(11)} & +\underbrace{\boldsymbol{v} \bullet \nabla \eta}_{(12)}+\omega \frac{\partial \eta}{\partial p}+\eta \nabla \bullet \boldsymbol{v}+\boldsymbol{k} \nabla \omega \times \frac{\partial v}{\partial p}-\boldsymbol{k} \bullet \nabla \times F \\
& +\underbrace{\frac{\partial}{\partial t}\left(f \frac{\partial}{\partial p}\left(\frac{T}{\Gamma}\right)\right)}_{(11)}+\underbrace{\boldsymbol{v} \bullet \nabla\left(f \frac{\partial}{\partial p}\left(\frac{T}{\Gamma}\right)\right)}_{(12)} \\
= & \frac{\partial}{\partial t}\left(f \frac{\partial}{\partial p}\left(\frac{T}{\Gamma}\right)\right)+\boldsymbol{v} \bullet \nabla\left(f \frac{\partial}{\partial p}\left(\frac{T}{\Gamma}\right)\right)
\end{aligned}
$$

After some mathematical developments (for further details see Appendix A) and taking the time-mean, the time-mean potential vorticity equation is then attained

$$
\begin{aligned}
\frac{\partial \bar{\Pi}}{\partial t}+\overline{\boldsymbol{v}} \bullet \nabla \bar{\Pi}= & \Theta+\bar{\zeta} \frac{\partial \bar{\omega}}{\partial p}-\bar{\omega} \frac{\partial \bar{\zeta}}{\partial p}-\boldsymbol{k} \nabla \bar{\omega} \times \frac{\partial \overline{\boldsymbol{v}}}{\partial p} \\
& +\frac{\partial}{\partial p}\left(\frac{\bar{T}}{\bar{\Gamma}}\right) \overline{\boldsymbol{v}} \bullet \nabla f-\frac{f}{\bar{\Gamma}} \frac{\partial \overline{\boldsymbol{v}}}{\partial \mathrm{p}} \bullet \nabla \bar{T} \\
& +f \frac{\bar{T}}{\bar{\Gamma}^{2}} \frac{\partial \overline{\boldsymbol{v}}}{\partial p} \bullet \nabla \bar{\Gamma}-f \frac{\partial}{\partial p}\left(\frac{\bar{T}}{\bar{\Gamma}^{2}} \overline{\boldsymbol{v}} \bullet \nabla \bar{\Gamma}\right) \\
& -f \frac{\partial}{\partial p}\left(\frac{\bar{T}}{\bar{\Gamma}^{2}} \frac{\partial \bar{\Gamma}}{\partial t}\right)
\end{aligned}
$$

where $\Theta$ is defined as

$$
\begin{aligned}
\Theta & =f \frac{\partial}{\partial p}\left(\frac{\bar{Q}}{\bar{\Gamma}}\right)+k \bullet \nabla \times \bar{F} \\
& =f \frac{\partial}{\partial p}\left(\frac{\bar{Q}}{\bar{\Gamma}}\right)+\frac{1}{a \cos \varphi}\left(\frac{\partial \bar{Y}}{\partial \lambda}-\frac{\partial \bar{X} \cos \varphi}{\partial \varphi}\right) .
\end{aligned}
$$

In Eq. (16), $\bar{Q}$ is the sum of the diabatic heating terms related to transient temperature fluxes, whereas $\bar{X}$ and $\bar{Y}$ are the sum of the frictional dissipative components with the terms related to transient momentum fluxes.

Noting that the second member of Eq. (15) is the sum of $\Theta$ with non-linear terms, as follows

$\frac{\partial \bar{\Pi}}{\partial t}+\bar{v} \bullet \nabla \bar{\Pi}=\Theta+$ non-linear terms.

Now considering only the stationary-eddy (asymmetric) components in Eq. (15) and neglecting all non-linear asymmetric terms, the equation of the stationary-eddy potential vorticity is obtained

$$
\begin{aligned}
& \frac{\partial \bar{\Pi}^{*}}{\partial t} \approx-(\overline{\boldsymbol{v}} \bullet \nabla \bar{\Pi})^{*}+f \frac{\partial}{\partial p}\left(\frac{\bar{Q}}{\bar{\Gamma}}\right)^{*} \\
&+\frac{1}{a \cos \varphi}\left(\frac{\partial \bar{Y}}{\partial \lambda}-\frac{\partial}{\partial \varphi} \bar{X} \cos \varphi\right)^{*} \\
& \frac{\partial \bar{\Pi}^{*}}{\partial t} \approx-(\bar{v} \bullet \nabla \bar{\Pi})^{*}+\Theta^{*} \approx 0
\end{aligned}
$$

According to Saltzman (1962), this approximation is reasonable when means are taken over a sufficiently long time period, such as an entire season. In this case, the term $\Theta^{*}$ can be interpreted as a forcing term of the stationary-eddy potential vorticity and is also called EFF. Since the local derivative of the stationary-eddy potential vorticity also tends to be neglected when considering an entire season (steady-state), the EFF tends to be balanced by advection, i.e., the advection pattern tends to be in phase opposition with the EFF pattern. Having in mind this EFF definition, it should be stressed that 
its analysis is essentially a diagnostic tool, not enabling studies of the development of the anomalies (onset/decay).

It is still worth emphasizing that the external forcing mechanisms of the atmospheric circulation (boundary conditions), such as topographic effects, diabatic fluxes at the lower atmospheric boundary are not incorporated in this definition. In fact, only internal (mechanical and thermal) processes are taken into consideration in the EFF formulation. Since these internal processes interact through positive and negative feedback mechanisms with the mean flow, they cannot be considered as independent forcing entities of the atmospheric flow. For instance, positive eddy feedback mechanisms have been shown to play a key role in the reinforcement of teleconnection patterns, such as the North Atlantic Oscillation (Rivière, 2009).

\subsection{EFF components}

In order to separate the contributions of different processes to the total forcing, the EFF can be expressed as a sum of seven additive components,

$\Theta^{*}=\sum_{n=1}^{7} f f_{n}(\lambda, \varphi, p)$.

Therefore, regions of positive (negative) values of $f f_{n}$ represent a cyclonic (anticyclonic) forcing of the stationary-eddy potential vorticity. It should be noted the possibility that large scale potential vorticity anomalies set up without being caused by any underlying forcing mechanism; in such case, under steady conditions, those anomalies will not be advected by the atmospheric flow, with the consequence that they would remain undetected by the present analysis. This possibility deserves further investigation, which falls outside the scope of this paper. In the present work it is assumed that the onset of circulations resulting in dry or wet winters in continental Portugal is due to forcing effects which reflect on different patterns of the empirical forcing function.

Substituting Eqs. (3), (4) and (6) in (16) and taking the zonal-mean departure, the component separation of the EFF is attained. The mathematical formulation of each component is as follows:

$f f_{1}=f \frac{\partial}{\partial p}\left(\frac{1}{\bar{\Gamma}}\left(\frac{\overline{\dot{q}_{\mathrm{R}}+\dot{q}_{\mathrm{F}}}}{c_{p}}\right)\right)^{*}$

is associated with friction and diabatic heating,

$f f_{2}=f \frac{\partial}{\partial p}\left(\frac{1}{\bar{\Gamma}}\left(\frac{\overline{\dot{q}_{L}}}{c_{p}}\right)\right)^{*}$

is associated with latent heat release,

$f f_{3}=-f \frac{\partial}{\partial p}\left(\frac{1}{\bar{\Gamma}}\left(\frac{\partial \overline{u^{\prime} T^{\prime}}}{\partial \lambda}+\frac{\partial}{\partial \varphi} \overline{v^{\prime} T^{\prime}} \cos \varphi\right)\right)^{*}$ is related to the differential divergence of the transient-eddy horizontal transports of enthalpy,

$f f_{4}=-f \frac{\partial}{\partial p}\left(\frac{1}{\bar{\Gamma}}\left(\frac{\partial \overline{\omega^{\prime} T^{\prime}}}{\partial \lambda}-\frac{R}{p c_{p}} \overline{\omega^{\prime} T^{\prime}}\right)\right)$

is associated with the differential divergence of the vertical transient-eddy transports of enthalpy,

$f f_{5}=(\boldsymbol{k} \bullet \nabla \times \bar{F})^{*}$

is linked to friction,

$$
\begin{aligned}
f f_{6}= & -\frac{1}{a^{2} \cos \varphi}\left[\frac{1}{\cos \varphi} \frac{\partial}{\partial \lambda}\left(\frac{\partial \overline{u^{\prime} v^{\prime}}}{\partial \lambda}+\frac{\partial}{\partial \varphi}{\overline{v^{\prime}}}^{2} \cos \varphi+{\overline{u^{\prime}}}^{2} \sin \varphi\right)\right. \\
& \left.-\frac{\partial}{\partial \varphi}\left(\frac{\partial{\overline{u^{\prime}}}^{2}}{\partial \lambda}+\frac{\partial}{\partial \varphi} \overline{u^{\prime} v^{\prime}} \cos \varphi-\overline{u^{\prime} v^{\prime}} \sin \varphi\right)\right]^{*}
\end{aligned}
$$

is associated with the transient horizontal transports of momentum,

$f f_{7}=-\frac{1}{a \cos \varphi} \frac{\partial}{\partial p}\left(\frac{\partial \overline{v^{\prime} \omega^{\prime}}}{\partial \lambda}-\frac{\partial}{\partial \varphi} \overline{u^{\prime} \omega^{\prime}} \cos \varphi\right)^{*}$

is related to the transient vertical transports of momentum.

For the second component, the rate of heat addition per unit mass due to condensation, $\dot{q}_{\mathrm{L}}$, was calculated indirectly from the water vapour continuity equation,

$$
\begin{aligned}
\overline{\dot{q}_{\mathrm{L}}}= & -L\left(\frac{\partial \bar{q}}{\partial t}+\overline{\boldsymbol{v} \bullet \nabla q}+\overline{\omega \frac{\partial q}{\partial p}}\right) \\
= & -L\left(\frac{\partial \bar{q}}{\partial t}+\overline{\boldsymbol{v} \bullet \nabla q}+\frac{\partial \overline{\omega q}}{\partial p}\right) \approx-L\left(\overline{\nabla \bullet v q}+\frac{\partial \overline{\omega q}}{\partial p}\right) \\
\overline{\dot{q}_{L}} \approx & -L\left(\frac{1}{a \cos \varphi} \frac{\partial \overline{u q}}{\partial \lambda}+\frac{1}{a \cos \varphi} \frac{\partial}{\partial \varphi} \overline{v q} \cos \varphi+\frac{1}{a \cos \varphi} \frac{\partial \overline{u^{\prime} q^{\prime}}}{\partial \lambda}\right. \\
& \left.+\frac{1}{a \cos \varphi} \frac{\partial}{\partial \varphi} \overline{v^{\prime} q^{\prime}} \cos \varphi+\frac{\partial \overline{\omega q}}{\partial p}+\frac{\partial \overline{\omega^{\prime} q^{\prime}}}{\partial p}\right)
\end{aligned}
$$

For the first component, the sum of the rates of heat addition per unit mass due to radiation and due to conduction and friction $\dot{q}_{\mathrm{R}}+\dot{q}_{\mathrm{F}}$, respectively, were indirectly computed from the energy conservation Eqs. (5) and (27), following a similar development. As such,

$$
\begin{aligned}
\overline{\dot{q}_{\mathrm{L}}+\dot{q}_{\mathrm{R}}+\dot{q}_{\mathrm{F}}} \approx & c_{p}\left(\frac{1}{a \cos \varphi} \frac{\partial \bar{u} \bar{T}}{\partial \lambda}+\frac{1}{a \cos \varphi} \frac{\partial}{\partial \varphi} \bar{v} \bar{T} \cos \varphi\right. \\
& +\frac{1}{a \cos \varphi} \frac{\partial \overline{u^{\prime} T^{\prime}}}{\partial \lambda}+\frac{1}{a \cos \varphi} \frac{\partial}{\partial \varphi} \overline{v^{\prime} T^{\prime}} \cos \varphi \\
& \left.+\frac{\partial \bar{\omega} \bar{T}}{\partial p}+\frac{\partial \overline{\omega^{\prime} T^{\prime}}}{\partial p}-\frac{R}{p c_{p}} \bar{\omega} \bar{T}-\frac{R}{p c_{p}} \overline{\omega^{\prime} T^{\prime}}\right)
\end{aligned}
$$


Consequently,

$\overline{\dot{q}_{\mathrm{R}}+\dot{q}_{\mathrm{F}}}=\overline{\dot{q}_{\mathrm{L}}+\dot{q}_{\mathrm{R}}+\dot{q}_{\mathrm{F}}}-\overline{\dot{q}}_{\mathrm{L}}$.

It is worth mentioning that due to the impossibility of obtaining the fifth component, related to frictional effects, the EFF considered here is the sum of the remaining six components.

\section{Data and methodology}

The NCEP/NCAR reanalysis dataset (Kistler et al., 2001) defined on a $2.5^{\circ} \times 2.5^{\circ}$ grid is used. Only data up to $250 \mathrm{hPa}$ is considered in the present study. Daily means for the period 1957-2008 are computed from 6-hourly data. Climate-mean values refer to averages calculated using the standard reference period from 1961 to 1990 (WMO, 1996). Since the application of the EFF is based on the fundamental assumption that the atmospheric properties (e.g., transient transports) are averaged over a relatively long time period, the time-means in all equations presented in the previous section refer to an entire winter period (DJF). The corresponding departures are then computed on a daily basis after seasonal correction (departures relative to the mean calendar day). Although the computations were performed for the entire Northern Hemisphere, as winter-mean ridges over the Eastern North Atlantic are the selected illustrative case study, the analysis presented here is focused only on the Euro-Atlantic sector. All partial derivatives were computed using centred finite differences and one-sided differences at the upper and lower boundaries (1000 and $250 \mathrm{hPa})$.

In order to quantify the synoptic wave activity, a simple approach after Blackmon (1976) and Blackmon et al. (1977) is used, where it is defined as the standard deviation of the bandpass filtered variability of the $500 \mathrm{hPa}$ height field, commonly referred to as "storm track". It was originally defined as the standard deviation of the band-pass (2-6 days) filtered variability of $500 \mathrm{hPa}$ geopotential heights, thus representing the sequence of westward propagating upper air troughs and ridges as the tropospheric counterparts of surface cyclones and high pressure systems (Wallace and Gutzler, 1981; Blackmon et al., 1984a, b; Wallace et al., 1988). The storm track results from Pinto et al. (2007) are considered here, which compute storm track activity from $2.5-8$ day bandpass filtered $500 \mathrm{hPa}$ geopotential height standard deviation (Christoph et al., 1995). The use of the Murakami recursive filter permits a faster determination of the results and produces equivalent results to those obtained with the Blackmon filter (cf. Christoph et al., 1995). This variable also includes some variability associated with high-pressure systems (which typically have longer time scales). Bandpass filtering is only applied for storm track computation, as raw daily data is used in all other fields presented here.

One of the purposes of the current study is to illustrate the applicability of the EFF patterns in diagnosing large-scale anomalies and in the identification of the physical forcing mechanisms that explain their occurrence. Aiming at isolating large-scale anomaly patterns over the North Atlantic, in particular strong anticyclonic ridges westwards of Iberia that are associated with severe precipitation deficits over Portugal, a set of six extremely dry winters are considered from a previous study (Santos et al., 2009b), namely 1980/81, 1982/83, 1991/92, 1999/00, 2001/02 and 2004/05. Several composite atmospheric fields for these dry winters are here compared with the corresponding climate-mean conditions (1961-1990).

\section{Case study}

\subsection{Storm track}

In a first step, the $500 \mathrm{hPa}$ geopotential height and storm track fields related to the occurrence of strong ridges over the Eastern North Atlantic were analyzed. The $500 \mathrm{hPa}$ geopotential height field shows a well-defined ridge westward of the Iberian Peninsula and extending northward to the British Isles in the dry winter composite (Fig. 1a), while a much more zonal (westerly) flow is observed in the winter climatology (Fig. 1b). In fact, the presence of a strong warm-core ridge westward of Iberia, with a nearly equivalent barotropic structure, is clearly unfavourable to rain generation over Western Iberia (Santos et al., 2007a). In these conditions, the stationary-eddy Eliassen-Palm fluxes also shown to maintain an anomalously strong difluence of the subtropical and eddy driven westerly jets over the North Atlantic Santos et al., 2009b). In fact, the enhanced ridge blocks the westerly propagation of the baroclinic disturbances (weather systems) over the North Atlantic, leading to a northward displacement of the storm track over the Eastern North Atlantic (Fig. 1a). This explains the lack of precipitation in Portugal, since such systems tend to carry moist and unstable air masses that are usually favourable to the occurrence of precipitation. The anomalous flow is particularly clear when analysing the storm track anomalies against climatology (Fig. 1c). A dipolar structure, similar to the North Atlantic Oscillation, but northeastwardly displaced, is quite evident (cf. also Ulbrich et al., 1999). While an important negative anomaly in the storm track occurs over the North Atlantic and south-western Iberia, strong positive anomalies occur over northern and central Europe. These results not only document again the link between anomalously strong North Atlantic ridges and important precipitation deficits in Portugal, but they also improve the characterization of these anomalies using a well-known methodology.

\subsection{Diabatic fluxes and transient transports}

Since the EFF encloses both mechanical (momentum transports) and thermal processes (enthalpy transports and diabatic heating), their respective patterns are analyzed before examining the EFF itself. More specifically, the patterns 
(a)

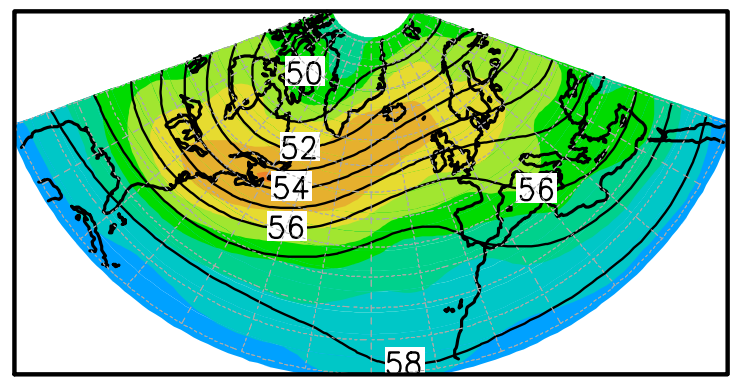

(b)

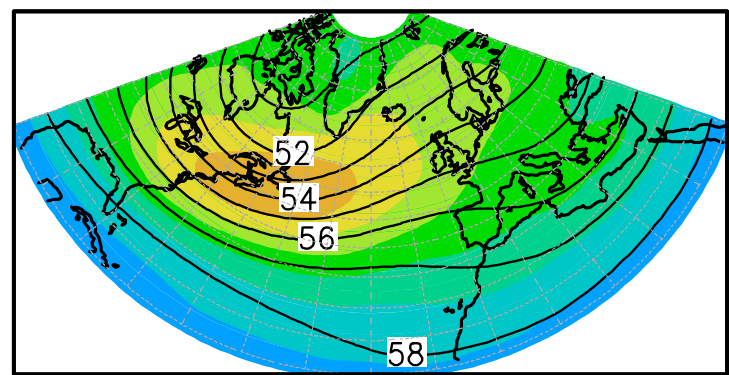

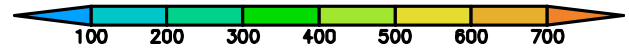

(c)
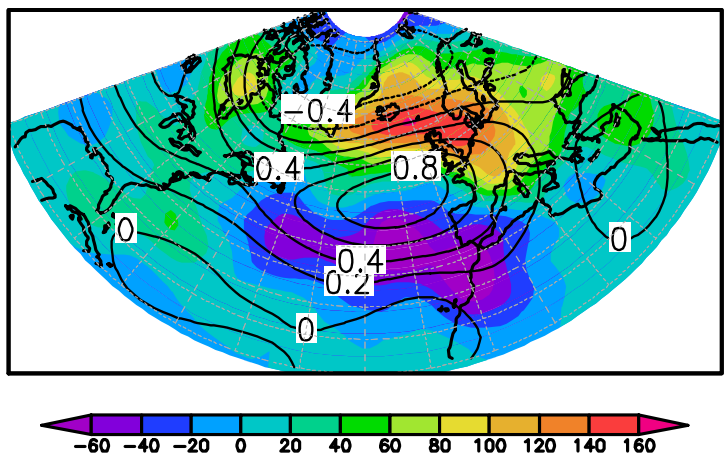

Fig. 1. Winter composites of the storm track (shading) at $500 \mathrm{hPa}$ (in gpm) and the corresponding $500 \mathrm{hPa}$ geopotential mean field (contours in $100 \mathrm{gpm}$ ) for the: (a) dry winters; (b) winter climatology; (c) the difference between the dry winters and winter climatology.

(a)
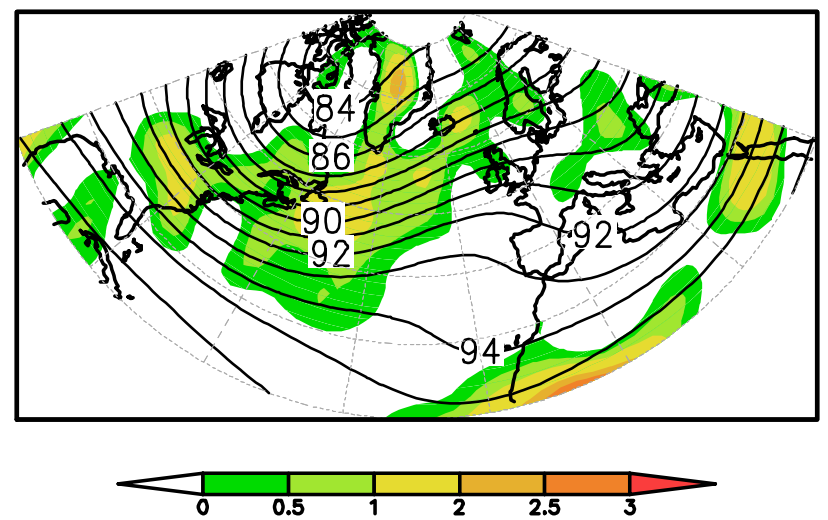

(b)
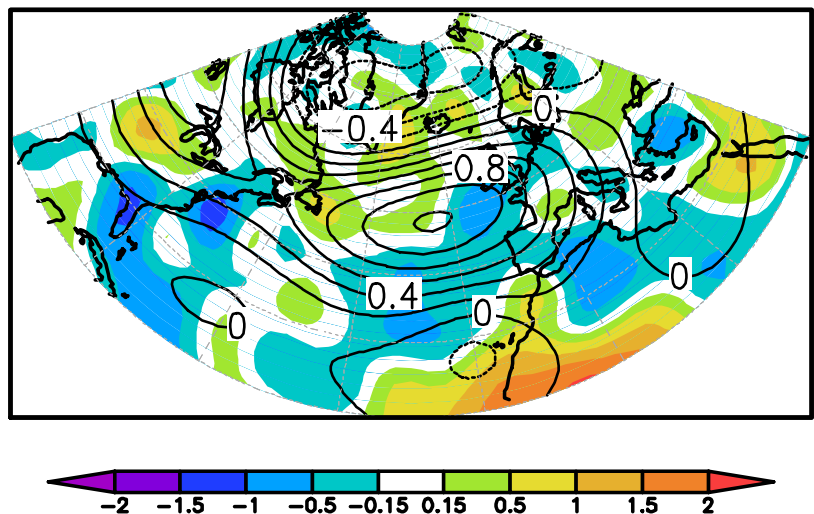

Fig. 2. Total rate of heat addition at $300 \mathrm{hPa}$ (shading in $10 \mathrm{~J} \mathrm{~s}^{-1}$ ) and corresponding $300 \mathrm{hPa}$ geopotential mean field (contours in 100 gpm) for the: (a) dry winters; (b) difference between the dry winters and the winter climatology.

of the diabatic heating term, calculated using Eq. (28), and of the transient horizontal enthalpy and momentum fluxes within the Euro-Atlantic sector are analysed and compared to the storm track features identified in the previous section. This procedure enables the isolation of some dynamical fea- tures associated with the selected anomalous circulation patterns, providing a better understanding of their physical nature.

The pattern of the total rate of heat addition, which is the basis for the first and second EFF components, depicts an 
(a)
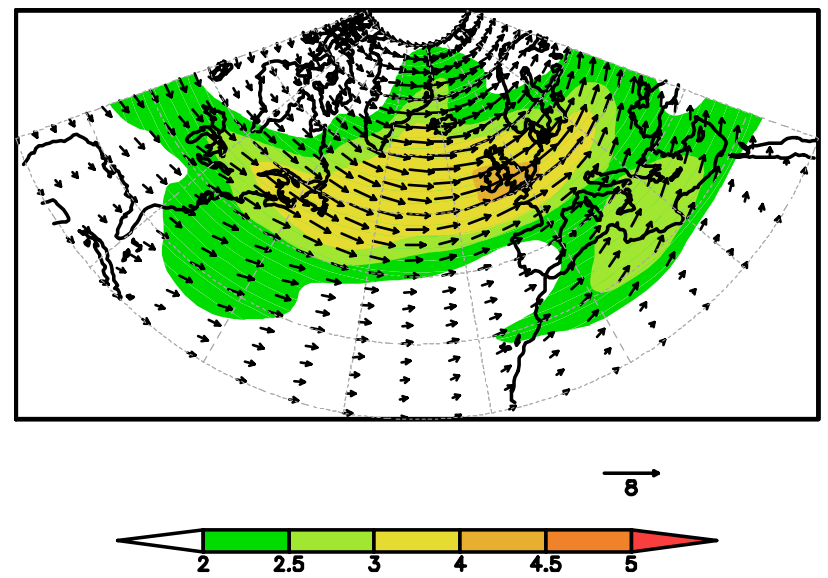

(b)
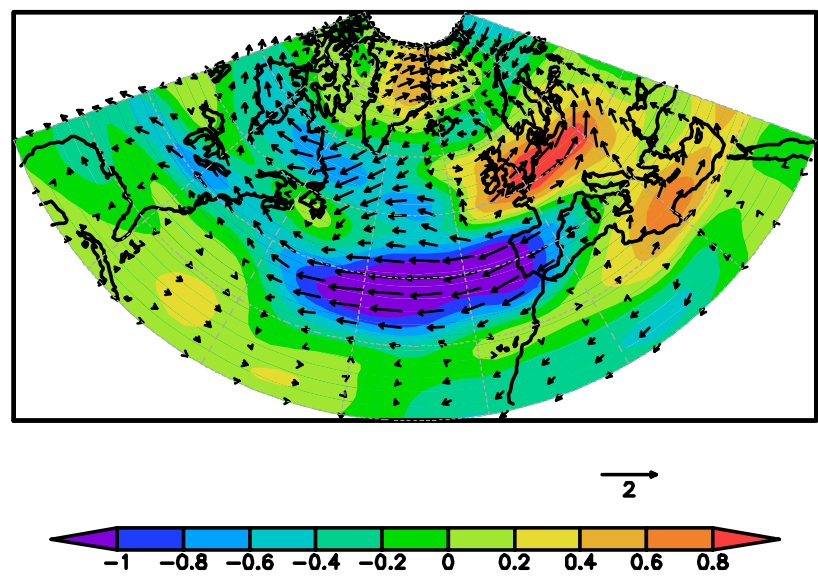

Fig. 3. Transient horizontal transports of momentum $\left(\overline{u^{\prime 2}} \hat{i}+\overline{u^{\prime} v^{\prime}} \hat{j}\right)$ at $300 \mathrm{hPa}$ (vectors in $10^{-2} \mathrm{~m}^{2} \mathrm{~s}^{-2}$ ) for the: (a) dry winters; (b) difference between the dry winters and the winter climatology. Shading represents the intensity of the fluxes in $10^{-2} \mathrm{~m}^{2} \mathrm{~s}^{-2}$.

(a)
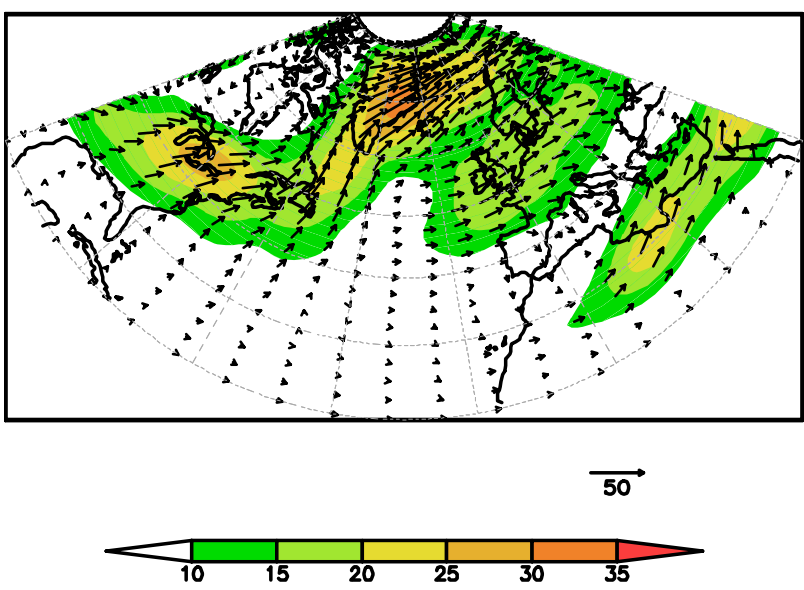

(b)

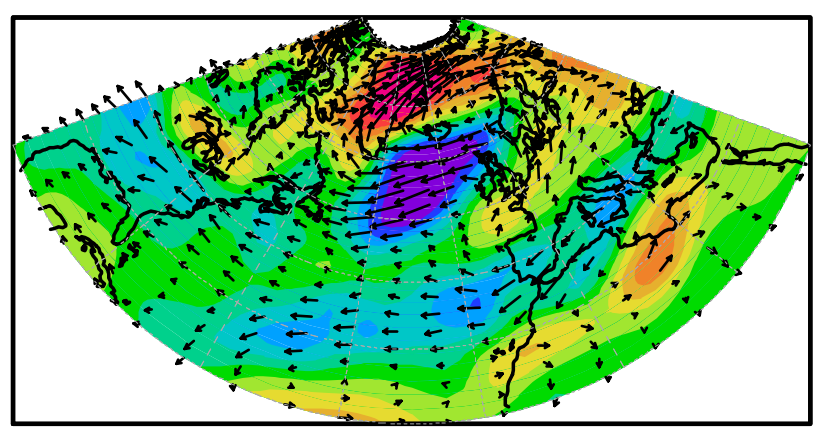

$\overrightarrow{20}$

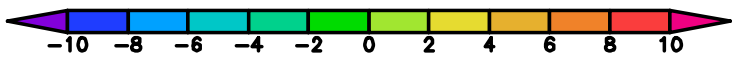

Fig. 4. The same as Fig. 3, but now for the transient horizontal transports of enthalpy $\left(\overline{u^{\prime} T^{\prime}} \hat{i}+\overline{v^{\prime} T^{\prime}} \hat{j}\right)$ at $300 \mathrm{hPa}$ (in $\mathrm{K} \mathrm{m} \mathrm{s}{ }^{-1}$ ).

enhanced positive forcing in the region upstream of the ridge and along the main storm track axis (Figs. 1 and 2). This pattern is very similar to the pattern associated with the latent heat release (not shown). In fact, the large correspondence between the maxima of the diabatic heating and the maxima of the storm track are physically coherent with high precipitation rates and nebulosity that are commonly found along the storm track, where significant amounts of latent heat are released in water vapour phase transitions (Black, 1998).

The transient horizontal enthalpy (Fig. 3) and momentum fluxes (Fig. 4), which are the basis for computing the third and sixth EFF components, reveal contrasting characteristics in the large-scale atmospheric flow. In effect, there is a sig- nificant decrease in the intensity of the transports over the eastern North Atlantic for the dry winters when compared to climatology (negative anomalies in Figs. 3b, 4b), since regions of the maximum transports are concentrated in the preferred locations of the storm track (Lau and Nath, 1991). Again they are also plainly consistent with the presence of a strong North Atlantic ridge, blocking the westerly propagation of the weather systems towards the Iberian Peninsula during dry winters. These results are in clear accordance with the results attained by Holopainen et al. (1982). Since the diabatic heating terms and the transient horizontal fluxes are directly related to the first, second, third and sixth EFF components (Eqs. 20, 21, 22 and 25), the above described 
(a)

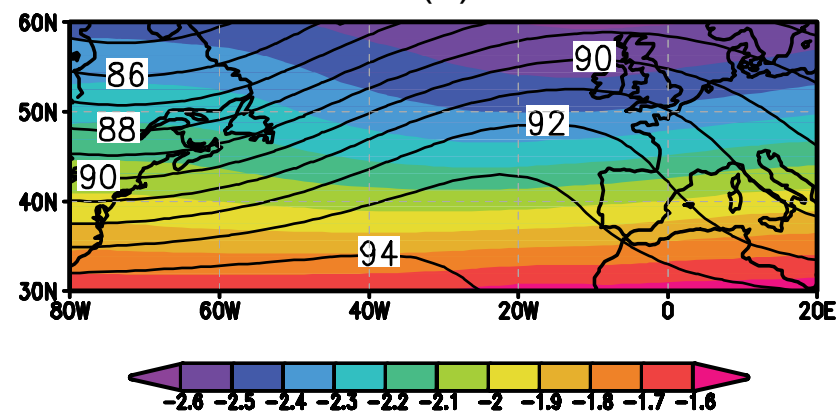

(b)

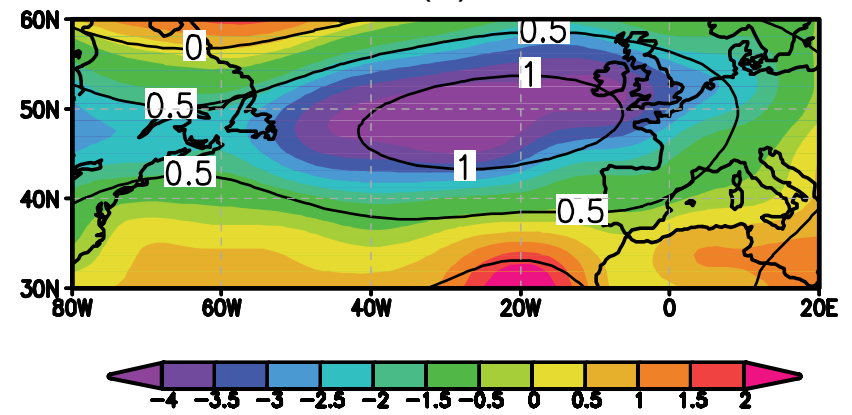

Fig. 5. Potential vorticity at $300 \mathrm{hPa}$ (in $10^{-3} \mathrm{~s}^{-1}$ ) and corresponding $300 \mathrm{hPa}$ geopotential mean field (contours in $100 \mathrm{gpm}$ ) for the: (a) dry winters; (b) difference between the dry winters and winter climatology (in $10^{-5} \mathrm{~s}^{-1}$ ).

(a)

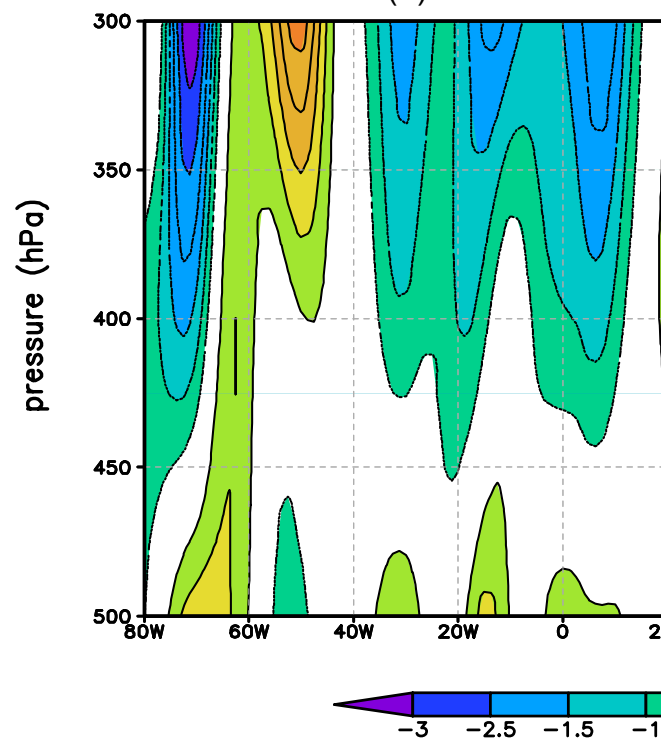

(b)

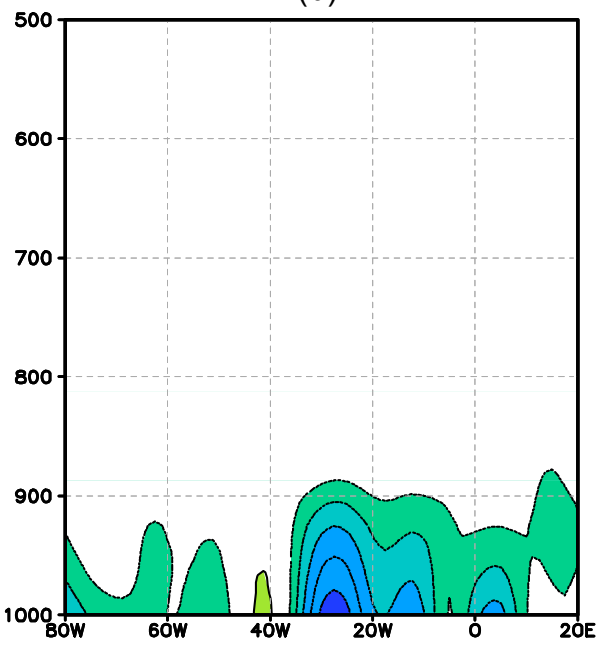

Fig. 6. Zonal cross-sections of the difference in the meridionally averaged $\left(30^{\circ} \mathrm{N}-60^{\circ} \mathrm{N}\right)$ EFF pattern between the dry winters and winter climatology over the North Atlantic $\left(80^{\circ} \mathrm{W}-20^{\circ} \mathrm{E}\right)$ and for the vertical layers (a) 500-300 $\mathrm{hPa}$ (in $10^{-10} \mathrm{~s}^{-2}$ ) and (b) $1000-500 \mathrm{hPa}$ (in $\left.10^{-9} \mathrm{~s}^{-2}\right)$.

patterns significantly influence the EFF patterns. The vertical transient transports are not presented here as they showed to be of secondary relevance in the EFF computation (see next section).

\subsection{Empirical Forcing Function}

The composite potential vorticity field (Eq. 10) at $300 \mathrm{hPa}$ for the dry winters and the corresponding deviations from the winter climatology are depicted in Fig. 5. By definition, this field tends to be proportional to minus the geopotential heights, explaining the negative values and the presence of a minimum in the area of the anticyclonic ridge and of a maximum over the geopotential trough over the Western North At- lantic (both fields tend to be in phase opposition). The strong meridional gradient of this field is still noteworthy (Fig. 5a). The anomalies depict a strong negative core over the North Atlantic within the range $45^{\circ}-55^{\circ} \mathrm{N}$ (Fig. 5b), which is a clear manifestation of the anomalously enhanced ridge observed during the selected dry winters.

The zonal cross-sections of the EFF over the selected Euro-Atlantic sector $\left(80^{\circ} \mathrm{W}-20^{\circ} \mathrm{E}\right)$ depict significant forcing values both at low $(1000-500 \mathrm{hPa})$ and high tropospheric levels $(500-300 \mathrm{hPa})$, though the near-surface forcing tends to have values one order of magnitude higher than at $300 \mathrm{hPa}$ (Fig. 6). The high values of the low tropospheric forcing are coherent with the presence of very strong 
(a)
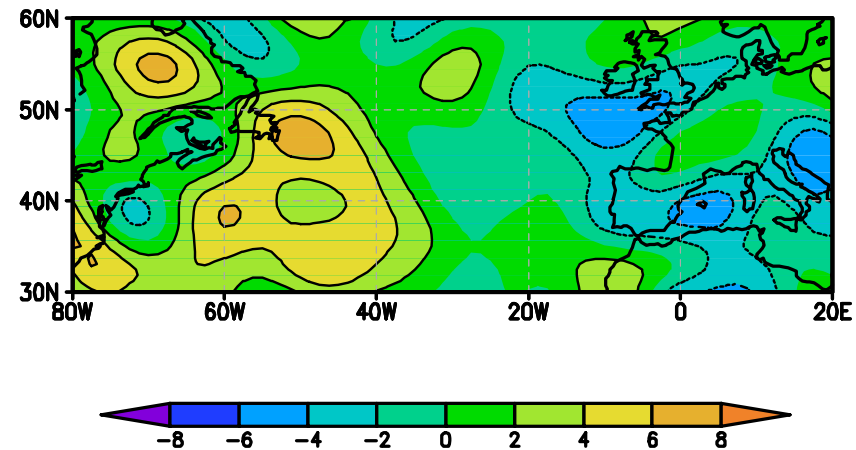

(b)

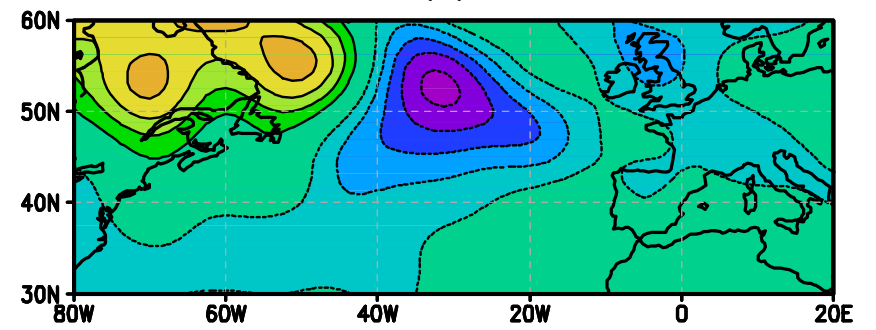

(c)

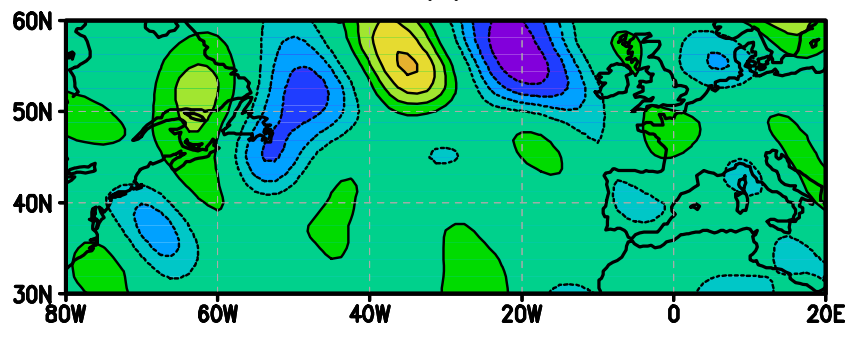

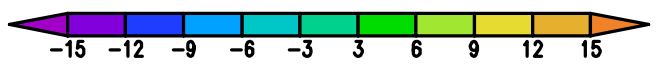

Fig. 7. Vertically-averaged (500-300 hPa): (a) EFF pattern (in $10^{-10} \mathrm{~s}^{-2}$ ); (b) third EFF component (in $10^{-11} \mathrm{~s}^{-2}$ ); (c) sixth EFF component (in $10^{-11} \mathrm{~s}^{-2}$ ) for the dry winters over the North Atlantic.

divergences/convergences at these levels due to diabatic processes that act as important factors in maintaining stationaryeddy potential vorticity. However, the cross-sections of the individual EFF components (not shown) reveal that the first component, which is associated with all diabatic heating processes but latent heat release, is the leading component not only at low tropospheric levels, but also at the upper troposphere, with values at least one order of magnitude larger than the other EFF components. Hence, the EFF pattern mainly reflects the rate of total heat addition and therefore, as a first approximation, it can be estimated using only the first EFF component defined by Eq. (20).

The vertically-averaged $(500-300 \mathrm{hPa})$ EFF pattern for the dry winters depicts an east-west dipolar structure over the North Atlantic (Fig. 7a), with essentially positive values westwards of $40^{\circ} \mathrm{W}$ of and an essentially negative values eastwards. This pattern is thus plainly coherent with the presence of a strong North Atlantic ridge during the selected winters, since the stationary-eddy cyclonic potential vorticity (positive EFF values) tends to be associated with geopotential troughs, while the stationary-eddy anticyclonic potential vorticity (negative EFF values) tends to be associated with geopotential ridges. Despite the leading role of the first component in maintaining the stationary-eddy potential vorticity, the second component, associated to latent heat release, is also important at low tropospheric levels, where humidity is essentially concentrated (not shown). Conversely, at higher tropospheric levels, the third and sixth components acquire a (relatively) higher relevance, documenting the relevance of the transient enthalpy and momentum transports in the maintenance of the stationary-eddy flow. These results are coherent with previous results using the Eliassen-Palm fluxes (cf., Fig. 9, Santos et al., 2009b).

The third and sixth components of the vertically averaged EFF at high tropospheric levels $(500-300 \mathrm{hPa})$ for the dry winters (Fig. 7b-c) reveal physically meaningful patterns. In the third EFF component for dry winters (Fig. 7b), the strong negative core over the North Atlantic is noteworthy. This pattern clearly supports the maintenance of the anomalously strong ridges. In the sixth EFF component, there is a very pronounced sequence of strong forcing cores along the northern border of the ridge (Fig. 7c). In fact, these forcing cores play an important role in aligning the eddy-driven polar jet and the storm track along their maxima by maintaining a sequence of positive and negative potential vorticity anomalies (Holopainen et al., 1982). Overall, the transient transports of both enthalpy and momentum at higher tropospheric levels are then shown to be essential for the maintenance of 
the large-scale asymmetric anomalies over the North Atlantic (Lau and Nath, 1991). The fourth and seventh components, associated with the vertical transient fluxes, are negligible throughout the troposphere (not shown) and can be generally discarded from the calculations of the EFF.

\section{Discussion and conclusions}

The formulation of the time-mean potential vorticity equation on isobaric surfaces (after Saltzman, 1962) is revisited in the present study. This less conventional formulation presents some attractive features. This formal development comprises a forcing term of the equation (EFF) that can be decomposed into seven additive components associated with different physical mechanisms. The role of different internal forcing mechanisms (both thermal and mechanical processes) in maintaining stationary eddies in the large-scale atmospheric motion can then be assessed.

The EFF was applied as a tool to diagnose large-scale stationary eddies associated with the occurrence of strong ridges over the Eastern North Atlantic, which are often precursors of severe droughts over Western Iberia. Results show that the EFF pattern (total forcing term) is dynamically coherent with the configuration of the geopotential height field. For such events, the EFF pattern depicts a clear dipolar structure over the North Atlantic that contributes to the maintenance of cyclonic (anticyclonic) potential vorticity upstream (downstream) of the anomalously strong ridges. The analysis of the individual components also shows that among the six calculated components (the fifth EFF component is associated to frictional effects and was not computed), the most important component throughout the troposphere is the first one, which is associated with diabatic heating (latent heat excluded). Nevertheless, latent heat release (second component) can also be important at low tropospheric levels, while transient horizontal enthalpy (third component) and momentum (sixth component) fluxes are important at high tropospheric levels. When compared with the latter components, vertical fluxes are negligible throughout the troposphere (fourth and seventh components). As such, the EFF pattern can be, at a first approximation, accurately estimated by computing only the first component. At a second approximation, the estimation of the EFF pattern at low (high) troposphere can be further improved by considering the second (third and sixth) components. No significant improvements can be made when considering the remaining components. Hence, they may be discarded in future studies.

Despite the previous results, in the interpretation of the EFF patterns some considerations must be born in mind. Although several internal (both mechanical and thermal) processes are taken into account in the EFF definition, the external forcing mechanisms of the atmospheric circulation, such as topographic effects, diabatic fluxes at the lower atmospheric boundary are not incorporated in this definition.
In fact, these processes can only be included as boundary conditions. Furthermore, taking into account that the EFF formulation derives from the equation of the time-mean potential vorticity over a relatively long time scale (e.g., a season), the EFF analysis only allows a diagnostic approach to the dynamical conditions, not enabling studies of generation/decay (development) of the anomalies. In fact, in this kind of analysis it can only be stated that an EFF component can contribute or not for the maintenance of a specific stationary eddy. Many previous studies have shown that transient eddies interact through positive and negative feedback mechanisms with the mean flow and cannot be considered as independent forcing entities of the atmospheric flow (e.g., Rivière, 2009).

Even taking into consideration the previous limitations of the EFF analysis, results give some evidence for considering the EFF patterns as a valuable tool in diagnosing stationaryeddy anomalies in the large-scale atmospheric motion, illustrated here for the occurrence of strong ridges over the Eastern North Atlantic. Moreover, by definition, the EFF enables the assessment of the different contributions made by internal (both mechanical and thermal) atmospheric processes in the maintenance of time-mean (e.g., seasonal mean) axially asymmetric anomalies in the atmospheric flow. This last property is a major motivation to consider the EFF patterns when analysing other large-scale atmospheric anomalies (e.g. teleconnections), which can be dealt with in future studies.

\section{Appendix A}

\section{Mathematical development of EFF}

The aim of this section is to guide the reader interested in the details involving the intricate mathematical development of the EFF. This development comprises the intermediate steps of the deduction between relation (11) and (15) of Sect. 2.1.

The following relations are going to be included during the mathematical development of the EFF. Let us considered the absolute vorticity equation, $\eta$,

$\eta=\zeta+f$,

from which the next equalities are obtained

$$
\begin{aligned}
\omega \frac{\partial \eta}{\partial p} & =\omega \frac{\partial(\zeta+f)}{\partial p} \\
& =\omega \frac{\partial \zeta}{\partial p}
\end{aligned}
$$

and

$$
\begin{aligned}
\eta \nabla \bullet v & =(\zeta+f) \nabla \bullet v \\
& =-\zeta \frac{\partial \omega}{\partial p}-f \frac{\partial \omega}{\partial p}
\end{aligned}
$$


From the potential vorticity definition (10) the following conditions are attained

$\frac{\partial}{\partial t}\left(f \frac{\partial}{\partial p}\left(\frac{T}{\Gamma}\right)\right)=f \frac{\partial}{\partial t}\left(\frac{1}{\Gamma} \frac{\partial T}{\partial p}\right)-f \frac{\partial}{\partial t}\left(\frac{T}{\Gamma^{2}} \frac{\partial \Gamma}{\partial p}\right)$,

$\boldsymbol{v} \bullet \nabla \Pi=\boldsymbol{v} \bullet \nabla \eta+\boldsymbol{v} \bullet \nabla\left(f \frac{\partial}{\partial p}\left(\frac{T}{\Gamma}\right)\right)$,

$\boldsymbol{v} \bullet \nabla\left(f \frac{\partial}{\partial p}\left(\frac{T}{\Gamma}\right)\right)=f \boldsymbol{v} \bullet \nabla \frac{\partial}{\partial p}\left(\frac{T}{\Gamma}\right)+\frac{\partial}{\partial p}\left(\frac{T}{\Gamma}\right) v \bullet \nabla f,(\mathrm{~A} 6)$

and

$\boldsymbol{v} \bullet \nabla\left(f \frac{\partial}{\partial p}\left(\frac{T}{\Gamma}\right)\right)=f \boldsymbol{v} \bullet \nabla\left(\frac{1}{\Gamma} \frac{\partial T}{\partial p}\right)-f \boldsymbol{v} \bullet \nabla\left(\frac{T}{\Gamma^{2}} \frac{\partial \Gamma}{\partial p}\right)$.

Let us also considered the following equalities

$\frac{\partial}{\partial p}\left(\frac{T}{\Gamma}\right) v \bullet \nabla f=-\frac{T}{\Gamma^{2}} \frac{\partial \Gamma}{\partial p} v \bullet \nabla f$

$f \frac{\partial}{\partial p}\left(\frac{1}{\Gamma} \boldsymbol{v} \bullet \nabla T\right)=\frac{f}{\Gamma} \frac{\partial \boldsymbol{v}}{\partial p} \bullet \nabla T+\frac{f}{\Gamma} \boldsymbol{v} \bullet \frac{\partial}{\partial p} \nabla T$

$$
-f v \bullet \nabla\left(\frac{T}{\Gamma^{2}}\right) \frac{\partial \Gamma}{\partial p}
$$

$-\frac{f \boldsymbol{v}}{\Gamma^{2}} \frac{\partial}{\partial p}(T \bullet \nabla \Gamma)=-f \frac{\partial}{\partial p}\left(\frac{T}{\Gamma^{2}} \boldsymbol{v} \bullet \nabla \Gamma\right)+f \frac{T}{\Gamma^{2}} \frac{\partial \boldsymbol{v}}{\partial p} \bullet \nabla \Gamma$

and

$\frac{\partial}{\partial p}\left(\frac{T}{\Gamma} \boldsymbol{v} \bullet \nabla f\right)=f \boldsymbol{v} \bullet \nabla\left(\frac{1}{\Gamma} \frac{\partial T}{\partial p}\right)-\frac{f}{\Gamma} \boldsymbol{v} \bullet \frac{\partial}{\partial p} \nabla T$.

From the energy conservation Eq. (5)

$\omega=\frac{Q}{\Gamma c_{p}}-\frac{1}{\Gamma}\left(\frac{\partial T}{\partial t}+\boldsymbol{v} \bullet \nabla T\right)$.

Let us remind that in Sect. 2.1. from vorticity Eq. (13) the following equality (14) was attained

$$
\begin{gathered}
\underbrace{\frac{\partial \eta}{\partial t}}_{(11)}+\underbrace{\boldsymbol{v} \bullet \nabla \eta}_{(12)}+\omega \frac{\partial \eta}{\partial p}+\eta \nabla \bullet \boldsymbol{v}+\boldsymbol{k} \nabla \omega \times \frac{\partial \boldsymbol{v}}{\partial p}-\boldsymbol{k} \bullet \nabla \times F \\
+\underbrace{\frac{\partial}{\partial t}\left(f \frac{\partial}{\partial p}\left(\frac{T}{\Gamma}\right)\right)}_{(11)}+\underbrace{\boldsymbol{v} \bullet \nabla\left(f \frac{\partial}{\partial p}\left(\frac{T}{\Gamma}\right)\right)}_{(12)} \\
=\frac{\partial}{\partial t}\left(f \frac{\partial}{\partial p}\left(\frac{T}{\Gamma}\right)\right)+v \bullet \nabla\left(f \frac{\partial}{\partial p}\left(\frac{T}{\Gamma}\right)\right)
\end{gathered}
$$

therefore

$$
\begin{aligned}
\frac{\partial \Pi}{\partial t}+v \bullet \nabla \Pi= & \frac{\partial}{\partial t}\left(f \frac{\partial}{\partial p}\left(\frac{T}{\Gamma}\right)\right)+v \bullet \nabla\left(f \frac{\partial}{\partial p}\left(\frac{T}{\Gamma}\right)\right) \\
& -\underbrace{\omega \frac{\partial \eta}{\partial p}}_{(\mathrm{A} 2)}-\underbrace{\eta \nabla \bullet v}_{(\mathrm{A} 3)}-k \nabla \omega \times \frac{\partial v}{\partial p}+k \bullet \nabla \times F
\end{aligned}
$$

after substituting the expressions

$$
\begin{aligned}
\frac{\partial \Pi}{\partial t}+v \bullet \nabla \Pi= & \underbrace{\frac{\partial}{\partial t}\left(f \frac{\partial}{\partial p}\left(\frac{T}{\Gamma}\right)\right)}_{(\mathrm{A} 4)}+\underbrace{v \bullet \nabla\left(f \frac{\partial}{\partial p}\left(\frac{T}{\Gamma}\right)\right)}_{(\mathrm{A} 6)} \\
& -\omega \frac{\partial \zeta}{\partial p}+\zeta \frac{\partial \omega}{\partial p}+\underbrace{f \frac{\partial \omega}{\partial p}}_{(\mathrm{A} 12)}-\mathrm{k} \nabla \omega \times \frac{\partial v}{\partial p}+k \bullet \nabla \times F
\end{aligned}
$$

consequently

$$
\begin{aligned}
\frac{\partial \Pi}{\partial t}+v \bullet \nabla \Pi= & -f \frac{\partial}{\partial p}\left(\frac{T}{\Gamma^{2}} \frac{\partial \Gamma}{\partial t}\right)+f \frac{\partial}{\partial p}\left(\frac{1}{\Gamma} \frac{\partial T}{\partial t}\right) \\
& +\underbrace{f v \bullet \nabla \frac{\partial}{\partial p}\left(\frac{T}{\Gamma}\right)}_{(\mathrm{A} 7)}+\underbrace{\frac{\partial}{\partial p}\left(\frac{T}{\Gamma}\right) v \bullet \nabla f}_{(\mathrm{A} 8)} \\
& -\omega \frac{\partial \zeta}{\partial p}+\zeta \frac{\partial \omega}{\partial p}+f \frac{\partial}{\partial p}\left(\frac{Q}{\Gamma}\right)- \\
& f \frac{\partial}{\partial p}\left(\frac{1}{\Gamma} \frac{\partial T}{\partial t}\right)-\underbrace{f \frac{\partial}{\partial p}\left(\frac{1}{\Gamma} v \bullet \nabla T\right)}_{(\mathrm{A} 9)} \\
& -\boldsymbol{k} \nabla \omega \times \frac{\partial v}{\partial p}+\boldsymbol{k} \bullet \nabla \times F
\end{aligned}
$$

from which after some simplifications the next equality is attained

$$
\begin{aligned}
\frac{\partial \Pi}{\partial t}+\boldsymbol{v} \bullet \nabla \Pi= & -f \frac{\partial}{\partial p}\left(\frac{T}{\Gamma^{2}} \frac{\partial \Gamma}{\partial t}\right)+\underbrace{f \boldsymbol{v} \bullet \nabla\left(\frac{1}{\Gamma} \frac{\partial T}{\partial p}\right)}_{(\mathrm{A} 11)} \\
& -\underbrace{\frac{f}{\Gamma^{2}} \boldsymbol{v} \bullet \frac{\partial T}{\partial p} \nabla \Gamma}_{(\mathrm{A} 10)}-\omega \frac{\partial \zeta}{\partial p}+\zeta \frac{\partial \omega}{\partial p}+f \frac{\partial}{\partial p}\left(\frac{Q}{\Gamma}\right) \\
& -\frac{f}{\Gamma} \frac{\partial \boldsymbol{v}}{\partial p} \bullet \nabla T-\frac{f}{\Gamma} \bullet \underbrace{\frac{\partial}{\partial p} \nabla T}_{(\mathrm{A} 11)}-\boldsymbol{k} \nabla \omega \times \frac{\partial \boldsymbol{v}}{\partial p} \\
& +\boldsymbol{k} \bullet \nabla \times F
\end{aligned}
$$

From Eq. (A16) substituting Eq. (A10) the following relation is attained

$$
\begin{aligned}
\frac{\partial \Pi}{\partial t}+\boldsymbol{v} \bullet \nabla \Pi= & -f \frac{\partial}{\partial p}\left(\frac{T}{\Gamma^{2}} \frac{\partial \Gamma}{\partial t}\right)+\frac{\partial}{\partial p}\left(\frac{T}{\Gamma}\right) \boldsymbol{v} \bullet \nabla f \\
& -f \frac{\partial}{\partial p}\left(\frac{T}{\Gamma^{2}} \boldsymbol{v} \bullet \nabla \Gamma\right)+f \frac{T}{\Gamma^{2}} \frac{\partial \boldsymbol{v}}{\partial p} \bullet \nabla \Gamma \\
& -\omega \frac{\partial \zeta}{\partial p}+\zeta \frac{\partial \omega}{\partial p}+ \\
& f \frac{\partial}{\partial p}\left(\frac{Q}{\Gamma}\right)-\frac{f}{\Gamma} \frac{\partial \boldsymbol{v}}{\partial p} \bullet \nabla T-\boldsymbol{k} \nabla \omega \times \frac{\partial \boldsymbol{v}}{\partial p} \\
& +\boldsymbol{k} \bullet \nabla \times F
\end{aligned}
$$


after taking the time-mean relations (15) and (16) are obtained and therefore equality (17)

$$
\begin{aligned}
\frac{\partial \bar{\Pi}}{\partial t}+\overline{\boldsymbol{v}} \bullet \nabla \bar{\Pi} & =f \frac{\partial}{\partial p}\left(\frac{\bar{Q}}{\bar{\Gamma}}\right)+\boldsymbol{k} \bullet \nabla \times \bar{F}+\text { non-linear terms } \\
& =\Theta+\text { non-linear terms }
\end{aligned}
$$

Acknowledgements. This work was supported by the project "Connections between precipitation extremes in Southern Europe and large-scale climate variability" (CRUP N A-28/08; DAAD D/07/13642). All maps were produced by the Grid Analysis and Display System developed at the Center for Ocean-LandAtmosphere Interactions. The authors are grateful to the two excellent reviewers who significantly contributed to improve the paper.

Topical Editor F. D'Andrea thanks two anonymous referees for their help in evaluating this paper.

\section{References}

Basset, H. A. and Ali, A. M.: Diagnostic of Cyclogenesis using Potential Vorticity, Atmosfera, 19(4), 213-234, 2006.

Black, R.: The Maintenance of Extratropical Intraseasonal Transient Eddy Activity in the GEOS-1 Assimilated Dataset, J. Atmos. Sci., 55, 3159-3175, 1998.

Blackmon, M. L.: A climatological spectral study of the $500 \mathrm{mb}$ geopotential height of the Northern Hemisphere, J. Atmos. Sci., 33, 1607-1623, 1976.

Blackmon, M. L., Lee, Y. H., and Wallace, J. M.: Horizontal structure of $500 \mathrm{mb}$ height fluctuations with long, intermediate and short time scales, J. Atmos. Sci., 41, 961-979, 1984a.

Blackmon, M. L., Lee, Y.-H., Wallace, J. M., Hsu, H.-H.: Time Variation of $500 \mathrm{mb}$ Height Fluctuations with Short, Medium and Long Time Scales, J. Atmos. Sci., 41, 981-991, 1984b.

Blackmon, M. L., Wallace, J. M., Lau, N.-C., and Mullen, S. L.: An observational study of the Northern hemisphere wintertime circulation, J. Atmos. Sci., 34, 1040-1053, 1977.

Bluestein, H. B.: Synoptic-Dynamic Meteorology in Middle Latitudes, Oxford University Press, Vol. II, 1993.

Chang, E. K. M. and Fu, Y.: Interdecadal variations in Northern Hemisphere winter storm track intensity, J. Climate, 22, 670688, 2002.

Chang, E. K. M.: Diabatic and Orographic Forcing of Northern Winter Stationary Waves and Storm Tracks, J. Climate, 15, 642$658,2009$.

Charney, J. G.: The dynamics of long waves in a barocline westerly current, J. Meteorol., 4, 135-163, 1947.

Chen, P., Hoerling, M., and Dole, R.: The Origin of the Subtropical Anticyclones, J. Atmos. Sci., 58, 1827-1835, 2001.

Christoph, M., Ulbrich, U., and Haak, U.: Faster Determination of the Intraseasonal Variability of Storm tracks Using Murakami's Recursive Filter, Mon. Weather Rev., 123, 578-581, 1995.

Davis, R. E., Hayden, B. P., Gay, D. A., Phillips, W. L., and Jones, G. V.: The North Atlantic Subtropical Anticyclone, J. Climate, 10, 728-744, 1997.

Eady, E. T.: Long waves and cyclone waves, Tellus, 1, 33-52, 1949.

Edmon, H. J., Hoskins, B. J., and McIntyre, M. E.: Eliassen-Palm cross sections for the troposphere, J. Atmos. Sci., 37, 2600-2616, 1980.

Ertel, E.: Ein neuer hydrodynamischer Wirbelsatz, Meteor. Z., 59, 277-281, 1942.

García-Herrera, R., Paredes, D., Trigo, R., Trigo, I., Hernández, E., Barriopedro, D., and Mendes, M.: The Outstanding 2004/05 Drought in the Iberian Peninsula: Associated Atmospheric Circulation, J. Hydrometeorol., 8, 483-498, 2007.

Hanson, C. E., Palutikof, J. P., Livermore, M. T. J., Barring, L., Bindi, M., Corte-Real, J., Duaro, R., Giannakopoulos, C., Good, 
P., Holt, T., Kundzewicz, Z., Leckebush, G., Moriondo, M., Radziejewski, M., Santos, J., Schlyter, P., Schwarb, M., Stjernquist, I., and Ulbrich, U.: Modelling the Impact of Climate Extremes: An overview of the Project, Prudence Special Issue, Clim. Change, 81, (1), 163-177, 2007.

Hartmann, D. H.: On potential vorticity and transport in the stratosphere, J. Atmos. Sci., 34, 968-977, 1977.

Holton, J. R.: An Introduction to Dynamic Meteorology, Elsevier, 2004.

Holopainen, E., Ronto, L., and Lau, N.: The Effect of Large-Scale Transient Eddies on the Time-mean flow in the Atmosphere, J. Atmos. Sci., 39, 1972-1984, 1982.

Hoskins, B. J., McIntyre, M. E., and Robertson, A. W.: On the Use of Significance of Isentropic Potential Vorticity Maps, Q. J. Roy. Meteorol. Soc., 111(470), 877-946, 1985.

Hoskins, B. J. and Valdes, P. J.: On the existence of storm tracks, J. Atmos. Sci., 47, 1854-1864, 1990.

Hurrell, J. W.: Decadal Trends in the North Atlantic Oscillation: Regional Temperatures and Precipitation, Science, 269, 676679, 1995.

Kistler, R., Kalnay, E., Collins, W., et al.: The NCEP/NCAR 50Year Reanalysis: Monthly-Means CD-ROM and Documentation, B. Am. Meteorol. Soc., 82, 247-267, 2001.

Lau, N. and Nath, M.: Variability of the Baroclinic Transient Eddy Forcing Associated with Monthly Changes in the Midlatitude Storm Tracks, J. Atmos. Sci., 48, 2589-2613, 1991.

Lau, N. and Wallace, J. M.: On the distribution of horizontal transports by transient eddies in the northern wintertime circulation., J. Atmos. Sci., 36, 1844-1861, 1979.

Lolis, C. J., Metaxas, D. A. and Bartzokas, A.: On the Intra-annual Variability of Atmospheric Circulation in Mediterranean Region, Int. J. Climatol., 28, 1339-1355, 2008.

Mendes, D. and Mendes, M. D.: Climatology of cyclones, anticyclones and storm tracks: revision of concepts, Rev. Bras. Geof., 22(2), 127-134, 2004.

Peixoto, J. P. and Oort, A. H.: Physics of Climate, American Institute of Physics, New York, 1992.

Pinto, J. G., Ulbrich, U., Leckebush, G. C., Spangehl, T., Reyes, M., and Zacharias, S.: Changes in storm track and cyclone activity in three SRES ensemble experiments with the ECHAM5/MPIOM1 GCN, Clim. Dynam., 29, 195-210, 2007.

Rivière, G.: Effect of Latitudinal Variations in Low-Level Baroclinicity on Eddy Life Cycles and Upper-Tropospheric WaveBreaking Processes, J. Atmos. Sci., 66, 1569-1592, 2009.

Salby, M. and Roger, P.: Fundamentals of Atmospheric Physics, Elsevier, Academic Press, 1996.

Saltzman, B.: Empirical Forcing Functions for the Large-Scale Mean Disturbances in the Atmosphere, Pure Appl. Geophys., 52, 173-188, 1962.

Santos, J. and Corte-Real, J.: Temperature Extremes in Europe and Large-Scale Circulation: HadCM3 future scenarios, Clim. Res., 31(1), 3-18, 2006.

Santos, J., Corte-Real, J., and Leite, S.: Weather regimes and their connection to the winter rainfall in Portugal, Int. J. Climatol., 25(1), 33-50, 2005.

Santos, J. and Leite, S.: Long-term variability of the temperature time series recorded at Lisbon, J. App. Stat., 36(3), 323-337, doi:10.1080/02664760802449159, 2009a.

Santos, J., Andrade, C., Corte-Real, J., and Leite, S.: The role of large-scale eddies in the occurrence of winter precipitation deficits in Portugal, Int. J. Climatol., 29(10), 1493-1507, 2009 b.

Santos, J., Corte-Real, J., and Leite, S.: Atmospheric Large-scale Dynamics During the 2004-2005 Winter Drought in Portugal, Int. J. Climatol., 27(5), 571-586, 2007a.

Santos, J., Corte-Real, J., Ulbrich, U., and Palutikof, J.: European Winter Precipitation Extremes and Surface Large-Scale Circulation: a Coupled Model and its Scenarios, Theor. Appl. Climatol., 87(1-4), 85-102, 2007b.

Santos, J. A., Pinto, J. G., and Ulbrich, U.: On the development of strong ridge episodes over the eastern North Atlantic, Geophys. Res. Lett., 36, L17804, doi:10.1029/2009GL039086, 2009c.

Savijärvi, H.: The interaction of the Monthly mean flow and largescale transient eddies in two different types. Part III: Potential vorticity balance, Geophysica, 15, 1-16, 1978.

Stephenson, D. B. and Held, I. M.: GCM response of northern winter stationary waves and storm tracks to increasing amounts of carbone dioxide, J. Climate, 6, 1859-1870, 1993.

Tank, A. M. G. K., Wijngaard, J. B., Konnen, G. P., Bohm, R., Demaree, G., Gocheva, A., Mileta, M., Pashiardis, S., Hejkrlik, L., Kern-Hansen, C., Heino, R., Bessemoulin, P., MullerWestermeier, G., Tzanakou, M., Szalai, S., Palsdottir, T., Fitzgerald, D., Rubin, S., Capaldo, M., Maugeri, M., Leitass, A., Bukantis, A., Aberfeld, R., Van Engelen, A. F. V., Forland, E., Mietus, M., Coelho, F., Mares, C., Razuvaev, V., Nieplova, E., Cegnar, T., Lopez, J. A., Dahlstrom, B., Moberg, A., Kirchhofer, W., Ceylan, A., Pachaliuk, O., Alexander, L. V., and Petrovic, P.: Daily dataset of 20th-century surface air temperature and precipitation series for the European Climate Assessment, Int. J. Climatol., 22, 1441-1453, 2002.

Trewartha, G. T. and Horn, L. H.: An Introduction to Climate, McGraw-Hill, 1980.

Ulbrich, U., Christoph, M., Pinto, J. G., and Corte-Real, J.: Dependence of Winter Precipitation over Portugal on NAO and Baroclinic Wave Activity, Int. J. Climatol., 19, 379-390, 1999.

Ulbrich, U., Pinto, J. G., Kupfer, H., Leckebusch, G. C., Spangehl, T., and Reyers, M.: Changing Northern Hemisphere Storm Tracks in an Ensemble of IPCC Climate Change Simulations, J. Climate, 21, 1669-1679, 2008.

Wang, C.: Atlantic Climate Variability and Its Associated Atmospheric Circulation Cells, J. Climate, 15, 1516-1536, 2002.

Wallace, J. M. and Gutzler, D. S.: Teleconnections in the geopotential height field during the Northern Hemisphere Winter, Mon Weather Rev., 109, 784-812, 1981.

Wallace, J. M., Lim, G., and Blackmon, M. L.: Relationship between Cyclone Tracks, Anticyclone Tracks and Barocline Wave Guides J. Atmos. Sci., 45, 439-462, 1988.

Wallace, J. M. and Hobbs, P. V. : Atmospheric Science: An Introductory Survey, Elsevier, 2006.

Wiin-Nielsen, A.: On the Structure of Atmospheric Waves in Middle Latitudes, Atmosfera, 16, 83-102, 2003.

WMO: Climatological Normals (CLINO) for the Period 19611990, World Meteorological Organization Doc. WMO/OMM, 847, Geneva, 1996.

Yin, J. H.: A Consistent Poleward Shift of the Storm Tracks in Simulations of 21st Century Climate, Geophys. Res. Lett., 32, 18, doi:10.1029/2005GL023684, 2005. 